\title{
Two open states of P2X receptor channels
}

\section{Milos B. Rokic and Stanko S. Stojilkovic*}

Section on Cellular Signaling, Program in Developmental Neuroscience, The Eunice Kennedy Shiver National Institute of Child Health and Human Development, National Institutes of Health, Bethesda, MD, USA

Edited by:

Rashid Giniatullin, University of

Eastern Finland, Finland

\section{Reviewed by:}

Baljit S. Khakh, University of California

Los Angeles, USA

Terrance M. Egan, Saint Louis

University, USA

Eric Boué-Grabot, University of

Bordeaux, France

\section{*Correspondence:}

Stanko S. Stojilkovic, Section on

Cellular Signaling, Program in

Developmental Neuroscience, The

Eunice Kennedy Shiver National

Institute of Child Health and Human

Development, National Institutes of

Health, Building 49, Room 6A36,

Bethesda, MD 20892-4510, USA

e-mail: stojilks@mail.nih.gov
The occupancy of the orthosteric ligand binding sites of P2X receptor (P2XR) channels causes the rapid opening of a small cation-permeable pore, followed by a gradual dilation that renders the pore permeable to large organic cations. Electrophysiologically, this phenomenon was shown using whole-cell current recording on P2X2R-, P2X2/X5R-, P2X4R- and P2X7R-expressing cells that were bathed in N-methyl-D-glucamine $\left(\mathrm{NMDG}^{+}\right)$-containing buffers in the presence and/or absence of small monovalent and divalent cations. The pore dilation of P2X4R and P2X7R caused a secondary current growth, whereas that of $\mathrm{P} 2 \mathrm{X} 2 \mathrm{R}$ showed a sustained kinetic coupling of dilation and desensitization, leading to receptor channel closure. The pore size of the P2X7R open and dilated states was estimated to be approximately $0.85 \mathrm{~nm}$ and greater than $1 \mathrm{~nm}$, respectively. The P2XR pore dilation was also observed in intact cells by measurement of fluorescent dye uptake/release, application of polyethylene glycols of different sizes, and atomic force microscopy. However, pore dilation was not observed the single channel level. Structural data describing the dilated state are not available, and the relevance of orthosteric and allosteric ligand interactions to pore dilation was not studied.

Keywords: ATP, purinergic receptor channels, gating, pore opening, pore dilation, NMDG, YO-PRO-1

\section{INTRODUCTION}

P2X receptors (P2XRs) are adenosine triphosphate (ATP)-gated ion channels expressed in numerous excitable and non-excitable cells from various species, including humans (hP2XRs), rats (rP2XRs), mice (mP2XRs), and zebrafish (zP2X4.1R), where they contribute to the control of many physiological functions (Chizh and Illes, 2001; Vassort, 2001; North, 2002; Burnstock and Knight, 2004; Stojilkovic, 2009; Khakh and North, 2012). Mammalian P2X subunits exist in seven isoforms with the ability to form homo- and heterotrimers in vitro and in native tissues (Nicke et al., 1998; Kaczmarek-Hajek et al., 2012). The structure of zP2X4.1R in the closed state revealed that the core domains of the three subunits mutually intertwine, forming a central vertical cavity. The ectodomain is projected $0.7 \mathrm{~nm}$ above the plasma membrane and contains three vestibules along its central axis (Kawate et al., 2009). The structure of zP2X4.1R in the open state showed that the key residues for ATP binding are located approximately $0.45 \mathrm{~nm}$ from the plasma membrane (Hattori and Gouaux, 2012). Consistent with mutagenesis studies (Ennion et al., 2000; Jiang et al., 2000; Roberts and Evans, 2006; Yan et al., 2006; Zemkova et al., 2007), this structure revealed that the residues K67, K69, N293, R295, and K313 (rP2X4R numbering) are crucial for the recognition of phosphate groups, while the adenine moiety lies deeper in the binding pocket and is stabilized by hydrogen bonding (Hattori and Gouaux, 2012).

When bathed in physiological ion conditions, P2XRs respond to ATP stimulation with amplitude-modulated inward currents (North, 2002). Using whole-cell recording, these currents can be described by four parameters: (i) the activation time; (ii) the peak current amplitude; (iii) the rate of decay of the current amplitude during a sustained receptor stimulation; and (iv) the rate of decay of the current amplitude during agonist washout (Coddou et al., 2011). The activation time decreases and the peak current amplitude and rate of receptor desensitization increase with elevation in agonist concentration, whereas the rate of current deactivation is independent of agonist concentration; this phenomenon is well documented for $\mathrm{rP} 2 \mathrm{X} 4 \mathrm{R}$ using an ultra-rapid perfusion system (Yan et al., 2006). At the single channel level, activation is defined as the transition from the closed state to the open state, desensitization as the transition from the open state to the closed-desensitized state, and deactivation as the transition from the open state to the closed state (Egan et al., 2006). The existence of naïve (not previously exposed to ATP) and experienced (previously exposed to ATP) receptor states has also been proposed, which may reflect the phosphorylation state of P2XRs or other mechanisms accounting for short-term (less than $30 \mathrm{~min}$ ) memory (Yan et al., 2010).

P2XRs are permeable to $\mathrm{Na}^{+}, \mathrm{K}^{+}$, and $\mathrm{Ca}^{2+}$ (Ding and Sachs, 1999), but the permeability to $\mathrm{Ca}^{2+}$ varies widely depending on the isoform (Evans et al., 1996; Soto et al., 1996; Virginio et al., 1998; Egan and Khakh, 2004). Some homomeric and heteromeric P2XRs also display a time-dependent modulation of ion selectivity by developing a new open state that permits relatively large cations to traverse the pore of the channel (Khakh et al., 1999; Virginio et al., 1999b). This phenomenon is called pore dilation, with the dilated pore representing a second open state with higher ion conductance. Our review focuses on the biophysical and biochemical aspects of pore dilation and transition to closed states, noting the isoform specificities. 


\section{HISTORICAL PERSPECTIVES}

Extracellular ATP was initially suggested to affect permeabilization of the plasma membrane by two mechanisms: through its interaction with P2 receptors and by using a P2-independent mechanism to make pores large enough to allow for the permeation of substances with molecular weights (MW) ranging between 300 and 900 (Cockcroft and Gomperts, 1979; Steinberg et al., 1987; Tatham and Lindau, 1990). Other authors suggested that both actions were mediated by P2 receptors and introduced the term "P2Z" to describe a putative permeabilizing $\mathrm{P} 2$ receptor that required for activation high concentrations of ATP, lower concentrations of Benzoylbenzoyl adenosine$5^{\prime}$-triphosphate (BzATP), and the removal of $\mathrm{Ca}^{2+} / \mathrm{Mg}^{2+}$ from the bath medium (Gordon, 1986). A receptor with a pharmacological profile typical of the P2Z receptor was cloned in 1996 and named P2X7R (Surprenant et al., 1996) and was able to permeabilize membranes (Virginio et al., 1999a). We now know that the rP2X7R transition from open to dilated states accounts for the permeabilizing action of ATP (Yan et al., 2008) and that the allosteric nature of $\mathrm{Ca}^{2+}$-dependent inhibition accounts for the stimulatory effects of divalent cation removal on ATP's potency for activation (Yan et al., 2011). Initial experiments with rP2X2R (Virginio et al., 1999b) and rP2X4R (Khakh et al., 1999) have shown that the transition from the open to dilated state is not a unique characteristic of P2X7R. Experiments with other channels also revealed that pore dilation is not a P2XRspecific phenomenon (Khakh and Lester, 1999; Chung et al., 2008).

\section{METHODS FOR STUDYING PORE DILATION}

In whole-cell recording, large organic cations such as $\mathrm{N}$-methylD-glucamine (NMDG ${ }^{+}$; MW 195) are commonly used to evaluate changes in the permeability of P2XR pores during sustained receptor activation. $\mathrm{NMDG}^{+}$is used alone or as a substitute for bath $\mathrm{Na}^{+}$in the presence of other inorganic cations. Prior to ATP application, cells expressing P2XR are impermeable to $\mathrm{NMDG}^{+}$. The uptake of nucleic acid-binding dyes, including YO-PRO-1 and TO-PRO-1, ethidium bromide (MW 394), and propidium iodide (MW 668), is also a standard tool for measuring cell permeabilization. YO-PRO-1 has been shown to permeate through $\mathrm{rP} 2 \mathrm{X} 2 \mathrm{R}, \mathrm{rP} 2 \mathrm{X} 4 \mathrm{R}, \mathrm{rP} 2 \mathrm{X} 7 \mathrm{R}, \mathrm{mP} 2 \mathrm{X} 7 \mathrm{R}$, and hP2X7R (Khakh et al., 1999; Virginio et al., 1999a; Hibell et al., 2000; Chessell et al., 2001; Yan et al., 2008). Ethidium bromide, most commonly used in the visualization of DNA and RNA in electrophoresis gels, was used to show changes in the permeability of human and mouse P2X7R (Stokes et al., 2010; Tran et al., 2010). This application is also the case with propidium iodide (Sun et al., 2010) and TO-PRO-1 (Mankus et al., 2011). The uptake of Lucifer Yellow (MW 457) was used to study the permeation of native $\mathrm{mP2X} 2 \mathrm{R}$ and $\mathrm{mP2X} 7 \mathrm{R}$ in taste bud cells (Hayato et al., 2007). Cellular leakage of the $\mathrm{Ca}^{2+}$ probes Fura-2 (MW ranging between 636 and 1001) and Fura-FF (MW ranging between 658 and 1023) has provided further useful information about the dilation of $\mathrm{rP} 2 \mathrm{X} 2 \mathrm{R}$ and rP2X7R (Yan et al., 2008; Khadra et al., 2012). In addition, the size of the dilated pore was measured by the application of differently sized polyethylene glycols; those having a MW greater than or equal to 5000 blocked the increase in cation permeability in cells expressing $\mathrm{rP} 2 \mathrm{X} 7 \mathrm{R}$, suggesting that the dilated pore is greater than $1 \mathrm{~nm}$ in diameter (Virginio et al., 1999a). Finally, rP2X4R (expressed in human 1321N1 cells) pore dilation was observed by atomic force microscopy (Shinozaki et al., 2009).

\section{PORE DILATION ACCOUNTS FOR BIPHASIC CURRENTS}

The current generated by naïve $\mathrm{rP} 2 \mathrm{X} 7 \mathrm{R}$ expressed in Human Embryionic Kidney 293 (HEK293) cells (Roger et al., 2008; Yan et al., 2008) and by hP2X7R expressed in Xenopus oocytes (Klapperstuck et al., 2001) features a biphasic response in wholecell recordings; the initial rapid rise in current $\left(\mathrm{I}_{1}\right)$ is accompanied by a secondary slow current growth $\left(\mathrm{I}_{2}\right)$, the rate of which increases with agonist concentration (Yan et al., 2010). The $\mathrm{I}_{2}$ is also evident when intracellular $\mathrm{Ca}^{2+}$ measurements are used to indicate the receptor activity in both amphotericin-perforated and intact cells (Yan et al., 2010). This phenomenon suggests that neither the expression system nor the washout of secondary messengers or intracellular ions accounts for this P2X7R behavior.

Substituting bath $\mathrm{Na}^{+}$with $\mathrm{NMDG}^{+}$permits current recordings in cells clamped at $-60 \mathrm{mV}$ and the detection of changes in reversal potential, as estimated by repetitive voltage-ramp pulses from $-80 \mathrm{mV}$ to $+80 \mathrm{mV}$. This finding was used to support the hypothesis of rP2X7R pore dilation (Yan et al., 2008). The substitution of $90 \%$ (Figure 1A) and 100\% (Figure 1B) of the extracellular $\mathrm{Na}^{+}$with $\mathrm{NMDG}^{+}$does not alter the biphasic response pattern of $\mathrm{rP} 2 \mathrm{X} 7 \mathrm{R}$ generated by the prolonged application of BzATP when $\mathrm{Ca}^{2+}, \mathrm{Mg}^{2+}$, and $\mathrm{K}^{+}$are all present in the bath medium. Under repetitive voltage-ramp pulses from -80 to $+80 \mathrm{mV}$, a positive shift was also found in the reversal potential (indicated by horizontal arrows in Figures 1D, E). The rate of reversal potential shift was highly comparable to the rate of $\mathrm{I}_{2}$ current growth (Figure 1G).

However, the time-course of rP2X7R agonist induced current was substantially different in cells bathed in $\mathrm{NMDG}^{+}$-containing medium lacking other cations (Figure 1C). The time-course consisted of an initial outward current, reflecting the movement of intracellular $\mathrm{Na}^{+}$through the channel pore, followed by a shift to an inward current, reflecting the gradually developing permeability to $\mathrm{NMDG}^{+}$and the lack of receptor deactivation after agonist washout (Jiang et al., 2005). This finding indicates that $\mathrm{NMDG}^{+}$cannot substitute for $\mathrm{Na}^{+}$in receptor deactivation (Yan et al., 2008), in contrast to $\mathrm{Ca}^{2+}$ (Figure 1B). Under these experimental conditions, a shift also occurred in the reversal potential (Figure 1F), indicating that the kinetics of decay from an outward to an inward current reflects pore dilation. Certainly, $\mathrm{NMDG}^{+}$ only partially substituted for inorganic cations as the conducting ion. This phenomenon is indicated by the peak amplitude of the inward current in Figures 1A-C. The time needed for the development of pore dilation was also observed in experiments where $\mathrm{NMDG}^{+}$was substituted for physiological cations during early and sustained agonist application (Figures $1 \mathrm{H}, \mathrm{I}$ ).

When expressed in Xenopus oocytes, rP2X4R exhibited a similar biphasic current response, with $\mathrm{I}_{2}$ developing slowly over several minutes. The biphasic current was also observed when using $\mathrm{NMDG}^{+}$-containing medium. The $\mathrm{I}_{2}$ growth occurred 


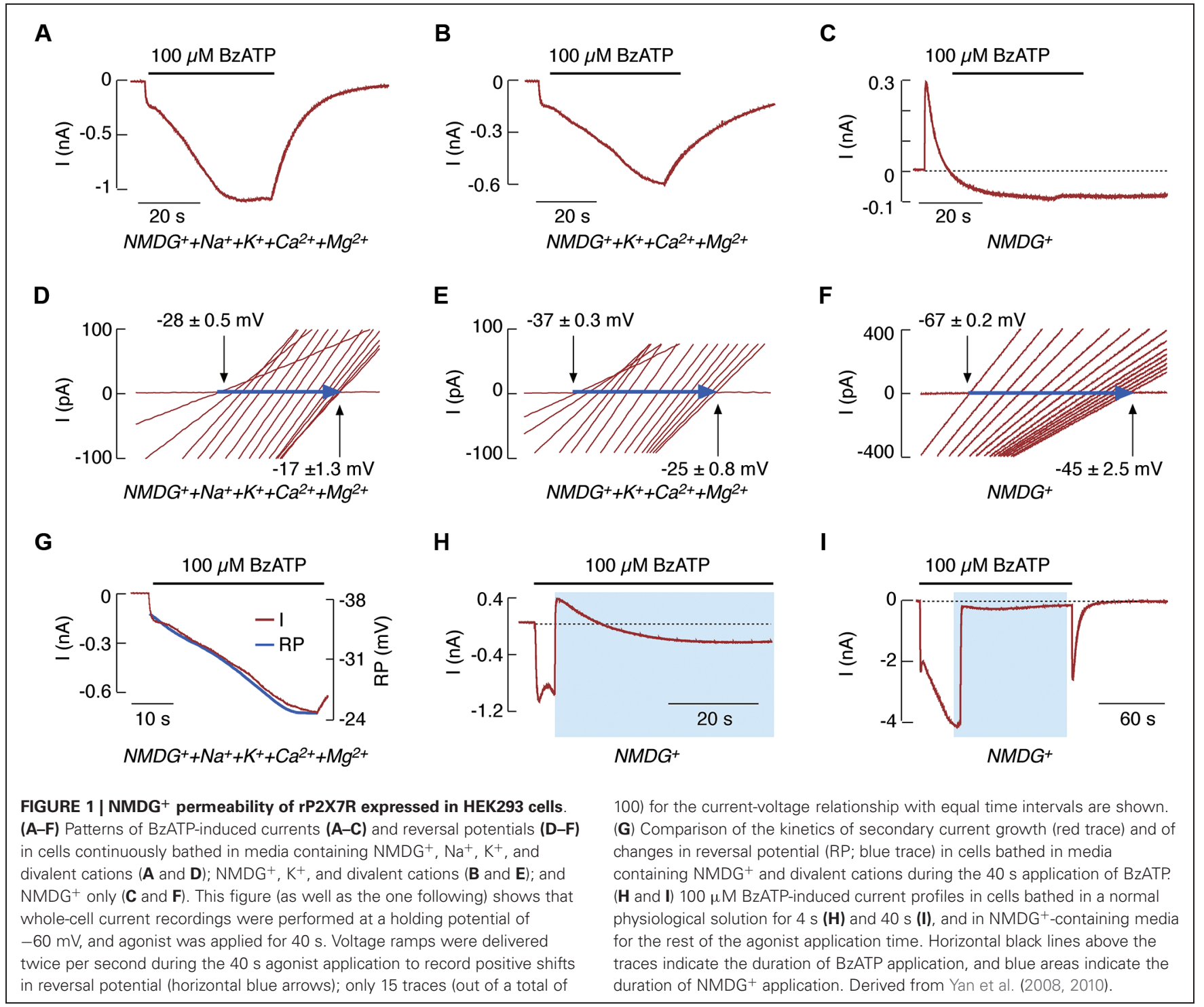

simultaneously with a positive shift in reversal potential and an uptake of YO-PRO-1 (Khakh et al., 1999). Other authors also observed pore dilation in $\mathrm{rP} 2 \mathrm{X} 4 \mathrm{R}$ expressed in Xenopus oocytes that were bathed in a low $\mathrm{Ca}^{2+}$ medium (Toulme et al., 2006).

Thus, the P2X4R and P2X7R permeation path is not a single step transition from a small to a large size pore. Instead, the receptor undergoes progressive dilation. Furthermore, the process of rP2X7R dilation was $\mathrm{Ca}^{2+}$-independent, in contrast to P2X7R gating, which was allosterically influenced by the presence of $\mathrm{Ca}^{2+}$ (Yan et al., 2011). However, rP2X4R pore dilation was blocked by bath $\mathrm{Ca}^{2+}$ (Khakh et al., 1999). A model of rP2X7R kinetics was proposed in accordance with these findings, suggesting the coupling of kinetic transitions from the open state to either the closed-desensitized state or to an additional open (dilated) state, which is also the sensitized/facilitated state. The transition to this open sensitized state is kinetically favored over the transition to the desensitized state, leading to the generation of a biphasic current response during the initial agonist application (Yan et al., 2010; Khadra et al., 2013).

\section{PORE DILATION IS MASKED BY RECEPTOR DESENSITIZATION}

When expressed in HEK293 cells, the full size rat receptor ( $\mathrm{rP} 2 \mathrm{X} 2 \mathrm{aR})$ and the splice variant missing $69 \mathrm{C}$-terminal amino acids (rP2X2bR) (Brandle et al., 1997; Koshimizu et al., 1998) each rapidly generated outward currents followed by slowly developing inward currents. Each also exhibited shifts in reversal potential when bathed in $\mathrm{NMDG}^{+}$- containing media and uptake of YO-PRO-1 when bathed in physiologically normal buffer. Together, these findings indicate pore dilation in both rP2X2Rs (Virginio et al., 1999b). However, when bathed in a $\mathrm{Ca}^{2+}$-containing medium, both forms of rP2X2Rs, as well as rP2X4R, generated desensitizing currents during sustained agonist application; notably, rP2X2bR was desensitized more rapidly than $\mathrm{rP} 2 \mathrm{X} 2 \mathrm{aR}$ (Figures 2A-C). The kinetics of pore dilation 
revealed the splice variant-dependent specificities of this process (Khadra et al., 2012). Cells clamped at $-60 \mathrm{mV}$ and stimulated with $100 \mu \mathrm{M}$ ATP showed an initial rapid outward current, reflecting an efflux of intracellular $\mathrm{Na}^{+}$through the pore. This activity was accompanied by a current decline, which also shifted directionality from outward to inward, reflecting the development of permeability to $\mathrm{NMDG}^{+}$(Figures 2D, E). In contrast, there was no shift from outward to inward current in HEK293 cells expressing rP2X4R (Figure 2F). In cells expressing $\mathrm{rP} 2 \mathrm{X} 2 \mathrm{aR}$ and $\mathrm{rP} 2 \mathrm{X} 2 \mathrm{bR}$, but not in those expressing $\mathrm{rP} 2 \mathrm{X} 4 \mathrm{R}$, the substitution of extracellular $\mathrm{Na}^{+}$with $\mathrm{NMDG}^{+}$also resulted in a strong time-dependent shift in reversal potential after the application of voltage-ramp pulses from -80 to $+80 \mathrm{mV}$ (Figures $2 \mathrm{G}-\mathbf{I}$ ). Finally, a correlation was found between the development of the $\mathrm{NMDG}^{+}$-induced current and the temporal changes in reversal potential (Figure 2D, inset).

Thus, the kinetics of desensitization for $\mathrm{rP} 2 \mathrm{X} 4 \mathrm{R}$, but not for $\mathrm{rP} 2 \mathrm{X} 2 \mathrm{aR}$ or $\mathrm{rP} 2 \mathrm{X} 2 \mathrm{bR}$, is identical in cells bathed in physiological and $\mathrm{NMDG}^{+}$-containing buffers. Furthermore, rP2X2aR and rP2X2bR, but not rP2X4R, dilate when bathed in $\mathrm{NMDG}^{+}$containing media. Recently, we showed that, in contrast to $\mathrm{rP} 2 \mathrm{X} 2 \mathrm{R}$ pore dilation, the removal of bath $\mathrm{Ca}^{2+}$ accounts for the difference in $\mathrm{rP} 2 \mathrm{X} 2 \mathrm{aR}$ and $\mathrm{rP} 2 \mathrm{X} 2 \mathrm{bR}$ desensitization kinetics in cells bathed in physiological and $\mathrm{NMDG}^{+}$-containing media
(Coddou et al., 2012). Both P2X2R homomers and rP2X2/X5R heteromers expressed in HEK293 cells dilate during sustained receptor activation (Compan et al., 2012). Channel clustering is not obligatory for $\mathrm{P} 2 \mathrm{X} 2 \mathrm{R}$ pore dilation, which most likely reflects permissive motions at the interface between the first and second transmembrane domains of neighboring subunits (Khakh and Egan, 2005). Finally, an experimentally supported mathematical model provides a rationale for the lack of sustained current growth in dilating $\mathrm{rP} 2 \mathrm{X} 2 \mathrm{Rs}$ by showing that dilated receptors also desensitize in the presence of $\mathrm{Ca}^{2+}$ (Khadra et al., 2012). The $\mathrm{Ca}^{2+}$-dependent transition from dilated to desensitized states does not occur in rP2X7R-expressing cells. This receptor only shows $\mathrm{Ca}^{2+}$-independent desensitization, resulting in a biphasic current response (Khadra et al., 2013).

\section{PANNEXIN-1 AND P2XR SIGNALING}

A comparative study of $\mathrm{NMDG}^{+}$and $\mathrm{YO}-\mathrm{PRO}-1$ uptake with wild type and mutant $\mathrm{rP} 2 \mathrm{X} 7 \mathrm{Rs}$ raised the possibility that these two molecules do not enter the cell by the same permeation pathway (Jiang et al., 2005). The search for a pathway accounting for YO-PRO-1 uptake led to the hypothesis that pannexin-1 (Panx1) could mediate pore formation and interleukin- $1 \beta$ release by rP2X7R (Pelegrin and Surprenant, 2006). Consistent with this hypothesis, Panx1 was found to co-immunoprecipitate with

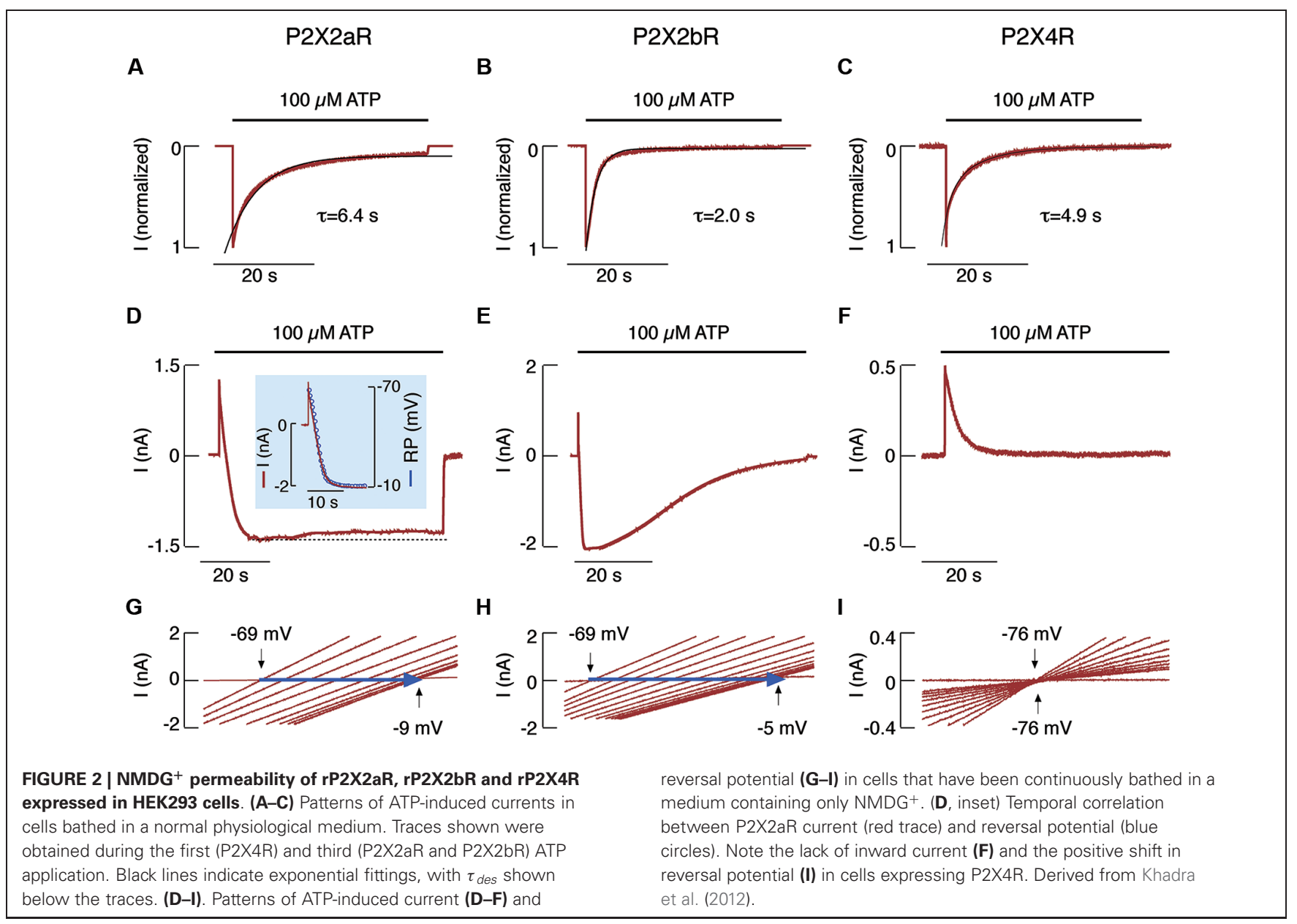


rP2X7R (Pelegrin and Surprenant, 2006; Li et al., 2011b) and other rP2XRs (Li et al., 2011b) when co-expressed in HEK293 cells.

However, several lines of evidence suggest that pore dilation is an intrinsic property of P2XR channels, independent of Panx1 expression and function. First, C6 astroglioma cells lack endogenously expressed Panx1, but the rP2X7R expressed in these cells dilates (Yan et al., 2008). Second, rP2X2R and rP2X7R dilation was not affected by overexpression of Panx1 or by blockading this channel with carbenoxolone (Chaumont and Khakh, 2008; Yan et al., 2008). Third, dilation of native mP2X4R bathed in a low $\mathrm{Ca}^{2+}$ medium was unaffected by carbenoxolone (Bernier et al., 2012). Fourth, RNAi targeting Panx1 did not affect native mP2X7R pore dilation (Alberto et al., 2013). Fifth, recent simultaneous measurement of membrane currents, fluorescent dye uptake, and permeation pathway sizing revealed that the dilated channel of $\mathrm{rP} 2 \mathrm{X} 7 \mathrm{R}$ allows the passage of molecules as large as $1.4 \mathrm{~nm}$ (Browne et al., 2013). Sixth, recent literature suggests that Panx1 may contribute to ATP release (Locovei et al., 2006; Huang et al., 2007; Iglesias et al., 2009; Li et al., 2011a); the role of Panx1 in ATP release but not in P2X7R pore dilation was further supported by experiments using Panx1 knockout bone marrowderived macrophages (Qu et al., 2011).

\section{THE ROLE OF CYTOSOLIC DOMAINS IN P2XR GATING}

The initial observation of the role of the C-terminus of rP2X7R in YO-PRO-1 uptake was reported by Surprenant et al. (1996). hP2X7R expressed in Xenopus oocytes also exhibited C-terminusdependent gating properties (Becker et al., 2008), but there were some differences in responses of $\mathrm{rP} 2 \mathrm{X} 7 \mathrm{R}$ and $\mathrm{hP} 2 \mathrm{X} 7 \mathrm{R}$ when expressed in HEK293 cells, probably reflecting the receptorspecific C-terminal domain structure (Rassendren et al., 1997). Studies comparing the wild type and C-terminal truncation forms of rP2X7R expressed in HEK293 cells and Xenopus oocytes further indicated the importance of the C-terminus for receptor dilation (Smart et al., 2003). Rat, but not mouse, P2X2aR showed pore dilation when expressed in Xenopus oocytes, thus suggesting the role of specific cytosolic domains as determinants of permeation in a state-specific manner (Eickhorst et al., 2002). The removal of a cysteine-rich segment of the intracellular juxta-membrane region of $\mathrm{rP} 2 \mathrm{X} 7 \mathrm{R}$ was reported to cause the loss of $\mathrm{NMDG}^{+}$ permeability without affecting YO-PRO-1 uptake (Jiang et al., 2005). This discrepancy can be explained by the instantaneous opening of the mutant receptor into the dilated state (Yan et al., 2008). The N-terminal T15 mutants also opened instantaneously into the dilated state in a protein kinase $\mathrm{C}$-independent manner (Yan et al., 2008, 2010), suggesting that N-terminal contributes to the control of transition from open to dilated state.

\section{FUTURE DIRECTIONS}

Although the crystal structures of the $\mathrm{zP} 2 \mathrm{X} 4.1 \mathrm{R}$ channel in both the ATP-bound open state and the apo-closed state have been solved (Kawate et al., 2009; Hattori and Gouaux, 2012), the structure of the dilated state is missing, presumably due in part to the lack of $\mathrm{N}$ - and C-termini in crystallization studies. The structural correlate of the P2X7R sensitization/facilitation state (Roger et al., 2008; Yan et al., 2010) is also missing. The dilated state is strongly ATP sensitized (Yan et al., 2010), which could imply structural changes in the ATP binding site and/or different orientations of bound ATP (Jiang et al., 2011). Pore dilation was not observed in single channel recording (Tatham and Lindau, 1990; Ding and Sachs, 1999; Riedel et al., 2007a,b) and the open- 1 state was estimated to be $0.85 \mathrm{~nm}$ (Riedel et al., 2007b). The reason for this discrepancy is not clear. Mutagenesis studies have identified specific regions and residues of P2XRs that influence pore dilation (Khakh and Egan, 2005; Yan et al., 2008; Sun et al., 2013), but further crystallization and mutagenesis studies are needed to better understand the transition from open to dilated states. It is also unclear which physiologically relevant metabolites from the cellular microenvironment permeate through the dilated $\mathrm{P} 2 \mathrm{XR}$ pore, or whether there are any allosteric up- or down-regulatory mechanisms that could convert the receptor to the dilated or naïve closed states. P2X7R exhibits a significant number of gene polymorphisms with strong pathophysiological implications in hP2XRs (Wesselius et al., 2011); further investigations should clarify whether the loss- or gain-of-function variants shows pore dilation. The development of pharmacological tools for altering the transition of P2XR pores from open to dilated states could help in dissecting the physiological significance of the two open states of P2XRs.

\section{ACKNOWLEDGMENTS}

This work was supported by the Intramural Research Program of the National Institute of Child Health and Human Development.

\section{AUTHOR CONTRIBUTIONS}

Both authors contributed to the writing of this review.

\section{REFERENCES}

Alberto, A. V., Faria, R. X., Couto, C. G., Ferreira, L. G., Souza, C. A., Teixeira, P. C., et al. (2013). Is pannexin the pore associated with the P2X7 receptor?. Naunyn Schmiedebergs Arch. Pharmacol. 386, 775-787. doi: 10.1007/s00210-0130868-x

Becker, D., Woltersdorf, R., Boldt, W., Schmitz, S., Braam, U., Schmalzing, G., et al. (2008). The P2X7 carboxyl tail is a regulatory module of P2X7 receptor channel activity. J. Biol. Chem. 283, 25725-25734. doi: 10.1074/jbc.m803855200

Bernier, L. P., Ase, A. R., Boue-Grabot, E., and Seguela, P. (2012). P2X4 receptor channels form large noncytolytic pores in resting and activated microglia. Glia 60, 728-737. doi: 10.1002/glia.22301

Brandle, U., Spielmanns, P., Osteroth, R., Sim, J., Surprenant, A., Buell, G., et al. (1997). Desensitization of the (P2X2) receptor controlled by alternative splicing. FEBS Lett. 404, 294-298. doi: 10.1016/S0014-5793(97)00128-2

Browne, L. E., Compan, V., Bragg, L., and North, R. A. (2013). P2X7 receptor channels allow direct permeation of nanometer-sized dyes. J. Neurosci. 33, $3557-$ 3566. doi: 10.1523/jneurosci.2235-12.2013

Burnstock, G., and Knight, G. E. (2004). Cellular distribution and functions of P2 receptor subtypes in different systems. Int. Rev. Cytol. 240, 31-304. doi: 10. 1016/s0074-7696(04)40002-3

Chaumont, S., and Khakh, B. S. (2008). Patch-clamp coordinated spectroscopy shows $\mathrm{P} 2 \mathrm{X} 2$ receptor permeability dynamics require cytosolic domain rearrangements but not Panx-1 channels. Proc. Natl. Acad. Sci. U S A 105, 12063 12068. doi: 10.1073/pnas.0803008105

Chessell, I. P., Grahames, C. B. A., Michel, A. D., and Humphrey, P. P. (2001). Dynamics of P2X7 receptor pore dilation: pharmacological and functional consequences. Drug. Dev. Res. 53, 60-65. doi: 10.1002/ddr.1171

Chizh, B. A., and Illes, P. (2001). P2X receptors and nociception. Pharmacol. Rev. 53, 553-568. 
Chung, M. K., Guler, A. D., and Caterina, M. J. (2008). TRPV1 shows dynamic ionic selectivity during agonist stimulation. Nat. Neurosci. 11, 555-564. doi: 10. 1038/nn.2102

Cockcroft, S., and Gomperts, B. D. (1979). ATP induces nucleotide permeability in rat mast cells. Nature 279, 541-542. doi: 10.1038/279541a0

Coddou, C., Leiva-Salcedo, E., Yan, Z., Li, S., Tomic, M., and Stojilkovic, S. (2012). Calcium increases $\mathrm{P} 2 \mathrm{X} 2$ receptor desensitization by an allosteric mechanism. Annual Neuroscience Meeting Abstract 641.01/C57.

Coddou, C., Yan, Z., Obsil, T., Huidobro-Toro, J. P., and Stojilkovic, S. S. (2011). Activation and regulation of purinergic P2X receptor channels. Pharmacol. Rev. 63, 641-683. doi: 10.1124/pr.110.003129

Compan, V., Ulmann, L., Stelmashenko, O., Chemin, J., Chaumont, S., and Rassendren, F. (2012). P2X2 and P2X5 subunits define a new heteromeric receptor with P2X7-like properties. J. Neurosci. 32, 4284-4296. doi: 10 1523/JNEUROSCI.6332-11.2012

Ding, S., and Sachs, F. (1999). Ion permeation and block of P2X(2) purinoceptors: single channel recordings. J. Membr. Biol. 172, 215-223. doi: 10. $1007 / \mathrm{s} 002329900598$

Egan, T. M., and Khakh, B. S. (2004). Contribution of calcium ions to P2X channel responses. J. Neurosci. 24, 3413-3420. doi: 10.1523/jneurosci.5429-03.2004

Egan, T. M., Samways, D. S., and Li, Z. (2006). Biophysics of P2X receptors. Pflugers Arch. 452, 501-512. doi: 10.1007/s00424-006-0078-1

Eickhorst, A. N., Berson, A., Cockayne, D., Lester, H. A., and Khakh, B. S. (2002). Control of P2X2 channel permeability by the cytosolic domain. J. Gen. Physiol. 120, 119-131. doi: 10.1085/jgp.20028535

Ennion, S., Hagan, S., and Evans, R. J. (2000). The role of positively charged amino acids in ATP recognition by human P2X1 receptors. J. Biol. Chem. 275, 2936129367. doi: 10.1074/jbc.m003637200

Evans, R. J., Lewis, C., Virginio, C., Lundstrom, K., Buell, G., Surprenant, A., et al. (1996). Ionic permeability of, and divalent cation effects on, two ATPgated cation channels (P2X receptors) expressed in mammalian cells. J. Physiol. 497(Pt 2), 413-422.

Gordon, J. L. (1986). Extracellular ATP: effects, sources and fate. Biochem. J. 233, 309-319.

Hattori, M., and Gouaux, E. (2012). Molecular mechanism of ATP binding and ion channel activation in P2X receptors. Nature 485, 207-212. doi: 10. 1038/nature 11010

Hayato, R., Ohtubo, Y., and Yoshii, K. (2007). Functional expression of ionotropic purinergic receptors on mouse taste bud cells. J. Physiol. 584, 473-488. doi: 10. 1113/jphysiol.2007.138370

Hibell, A. D., Kidd, E. J., Chessell, I. P., Humphrey, P. P., and Michel, A. D. (2000). Apparent species differences in the kinetic properties of $\mathrm{P} 2 \mathrm{X} 7$ receptors. Br. J. Pharmacol. 130, 167-173. doi: 10.1038/sj.bjp.0703302

Huang, Y. J., Maruyama, Y., Dvoryanchikov, G., Pereira, E., Chaudhari, N., and Roper, S. D. (2007). The role of pannexin 1 hemichannels in ATP release and cell-cell communication in mouse taste buds. Proc. Natl. Acad. Sci. U S A 104, 6436-6441. doi: 10.1073/pnas.0611280104

Iglesias, R., Dahl, G., Qiu, F., Spray, D. C., and Scemes, E. (2009). Pannexin 1: the molecular substrate of astrocyte "hemichannels". J. Neurosci. 29, 7092-7097. doi: 10.1523/jneurosci.6062-08.2009

Jiang, L. H., Rassendren, F., Mackenzie, A., Zhang, Y. H., Surprenant, A., and North, R. A. (2005). N-methyl-D-glucamine and propidium dyes utilize different permeation pathways at rat P2X7 receptors. Am. J. Physiol. Cell Physiol. 289, C1295-C1302. doi: 10.1152/ajpcell.00253.2005

Jiang, L. H., Rassendren, F., Surprenant, A., and North, R. A. (2000). Identification of amino acid residues contributing to the ATP-binding site of a purinergic P2X receptor. J. Biol. Chem. 275, 34190-34196. doi: 10.1074/jbc.m005481200

Jiang, R., Lemoine, D., Martz, A., Taly, A., Gonin, S., Prado De Carvalho, L., et al. (2011). Agonist trapped in ATP-binding sites of the P2X2 receptor. Proc. Natl. Acad. Sci. U S A 108, 9066-9071. doi: 10.1073/pnas.1102170108

Kaczmarek-Hajek, K., Lorinczi, E., Hausmann, R., and Nicke, A. (2012). Molecular and functional properties of $\mathrm{P} 2 \mathrm{X}$ receptors-recent progress and persisting challenges. Purinergic Signal. 8, 375-417. doi: 10.1007/s11302-012-9314-7

Kawate, T., Michel, J. C., Birdsong, W. T., and Gouaux, E. (2009). Crystal structure of the ATP-gated P2X4 ion channel in the closed state. Nature 460, 592-598. doi: $10.1038 /$ nature 08198

Khadra, A., Tomic, M., Yan, Z., Zemkova, H., Sherman, A., and Stojilkovic, S. S. (2013). Dual gating mechanism and function of P2X7 receptor channels. Biophys. J. 104, 2612-2621. doi: 10.1016/j.bpj.2013.05.006
Khadra, A., Yan, Z., Coddou, C., Tomic, M., Sherman, A., and Stojilkovic, S. S. (2012). Gating properties of the P2X2a and P2X2b receptor channels: experiments and mathematical modeling. J. Gen. Physiol. 139, 333-348. doi: 10. 1085/jgp.201110716

Khakh, B. S., Bao, X. R., Labarca, C., and Lester, H. A. (1999). Neuronal P2X transmitter-gated cation channels change their ion selectivity in seconds. Nat. Neurosci. 2, 322-330. doi: 10.1038/7233

Khakh, B. S., and Egan, T. M. (2005). Contribution of transmembrane regions to ATP-gated P2X2 channel permeability dynamics. J. Biol. Chem. 280, 6118-6129. doi: 10.1074/jbc.m411324200

Khakh, B. S., and Lester, H. A. (1999). Dynamic selectivity filters in ion channels. Neuron 23, 653-658. doi: 10.1016/s0896-6273(01)80025-8

Khakh, B. S., and North, R. A. (2012). Neuromodulation by extracellular ATP and P2X receptors in the CNS. Neuron 76, 51-69. doi: 10.1016/j.neuron.2012.09.024

Klapperstuck, M., Buttner, C., Schmalzing, G., and Markwardt, F. (2001). Functional evidence of distinct ATP activation sites at the human P2X7 receptor. J. Physiol. 534, 25-35. doi: 10.1111/j.1469-7793.2001.00025.x

Koshimizu, T., Tomic, M., Van Goor, F., and Stojilkovic, S. S. (1998). Functional role of alternative splicing in pituitary $\mathrm{P} 2 \mathrm{X} 2$ receptor-channel activation and desensitization. Mol. Endocrinol. 12, 901-913. doi: 10.1210/me.12.7. 901

Li, S., Bjelobaba, I., Yan, Z., Kucka, M., Tomic, M., and Stojilkovic, S. S. (2011a). Expression and roles of pannexins in ATP release in the pituitary gland. Endocrinology 152, 2342-2352. doi: 10.1210/en.2010-1216

Li, S., Tomic, M., and Stojilkovic, S. S. (2011b). Characterization of novel Pannexin 1 isoforms from rat pituitary cells and their association with ATP-gated P2X channels. Gen. Comp. Endocrinol. 174, 202-210. doi: 10.1016/j.ygcen.2011.08. 019

Locovei, S., Bao, L., and Dahl, G. (2006). Pannexin 1 in erythrocytes: function without a gap. Proc. Natl. Acad. Sci. U S A 103, 7655-7659. doi: 10.1073/pnas. 0601037103

Mankus, C., Rich, C., Minns, M., and Trinkaus-Randall, V. (2011). Corneal epithelium expresses a variant of $\mathrm{P} 2 \mathrm{X} 7$ receptor in health and disease. PLoS One 6:e28541. doi: 10.1371/journal.pone.0028541

Nicke, A., Baumert, H. G., Rettinger, J., Eichele, A., Lambrecht, G., Mutschler, E., et al. (1998). P2X1 and P2X3 receptors form stable trimers: a novel structural motif of ligand-gated ion channels. EMBO J. 17, 3016-3028. doi: 10. 1093/emboj/17.11.3016

North, R. A. (2002). Molecular physiology of P2X receptors. Physiol. Rev. 82, 1013-1067. doi: 10.1152/physrev.00015.2002

Pelegrin, P., and Surprenant, A. (2006). Pannexin-1 mediates large pore formation and interleukin-1beta release by the ATP-gated P2X7 receptor. EMBO J. 25, 5071-5082. doi: 10.1038/sj.emboj.7601378

Qu, Y., Misaghi, S., Newton, K., Gilmour, L. L., Louie, S., Cupp, J. E., et al. (2011). Pannexin-1 is required for ATP release during apoptosis but not for inflammasome activation. J. Immunol. 186, 6553-6561. doi: 10.4049/jimmunol. 1100478

Rassendren, F., Buell, G. N., Virginio, C., Collo, G., North, R. A., and Surprenant, A. (1997). The permeabilizing ATP receptor, P2X7. Cloning and expression of a human cDNA. J. Biol. Chem. 272, 5482-5486. doi: 10.1074/jbc.272.9. 5482

Riedel, T., Lozinsky, I., Schmalzing, G., and Markwardt, F. (2007a). Kinetics of P2X7 receptor-operated single channels currents. Biophys. J. 92, 2377-2391. doi: 10. 1529/biophysj.106.091413

Riedel, T., Schmalzing, G., and Markwardt, F. (2007b). Influence of extracellular monovalent cations on pore and gating properties of $\mathrm{P} 2 \mathrm{X} 7$ receptor-operated single-channel currents. Biophys. J. 93, 846-858. doi: 10.1529/biophysj.106. 103614

Roberts, J. A., and Evans, R. J. (2006). Contribution of conserved polar glutamine, asparagine and threonine residues and glycosylation to agonist action at human P2X1 receptors for ATP. J. Neurochem. 96, 843-852. doi: 10.1111/j.1471-4159. 2005.03593.X

Roger, S., Pelegrin, P., and Surprenant, A. (2008). Facilitation of P2X7 receptor currents and membrane blebbing via constitutive and dynamic calmodulin binding. J. Neurosci. 28, 6393-6401. doi: 10.1523/jneurosci.0696-08. 2008

Shinozaki, Y., Sumitomo, K., Tsuda, M., Koizumi, S., Inoue, K., and Torimitsu, K. (2009). Direct observation of ATP-induced conformational changes in single P2X4 receptors. PLoS Biol. 7:e103. doi: 10.1371/journal.pbio.1000103 
Smart, M. L., Gu, B., Panchal, R. G., Wiley, J., Cromer, B., Williams, D. A., et al. (2003). P2X7 receptor cell surface expression and cytolytic pore formation are regulated by a distal C-terminal region. J. Biol. Chem. 278, 8853-8860. doi: 10. 1074/jbc.m211094200

Soto, F., Garcia-Guzman, M., Gomez-Hernandez, J. M., Hollmann, M., Karschin, C., and Stuhmer, W. (1996). P2X4: an ATP-activated ionotropic receptor cloned from rat brain. Proc. Natl. Acad. Sci. U S A 93, 3684-3688. doi: 10.1073/pnas.93. 8.3684

Steinberg, T. H., Newman, A. S., Swanson, J. A., and Silverstein, S. C. (1987). ATP4permeabilizes the plasma membrane of mouse macrophages to fluorescent dyes. J. Biol. Chem. 262, 8884-8888.

Stojilkovic, S. S. (2009). Purinergic regulation of hypothalamopituitary functions. Trends Endocrinol. Metab. 20, 460-468. doi: 10.1016/j.tem.2009.05.005

Stokes, L., Fuller, S. J., Sluyter, R., Skarratt, K. K., Gu, B. J., and Wiley, J. S. (2010). Two haplotypes of the P2X7 receptor containing the Ala-348 to Thr polymorphism exhibit a gain-of-function effect and enhanced interleukin-1beta secretion. FASEB J. 24, 2916-2927. doi: 10.1096/fj.09-150862

Sun, C., Chu, J., Singh, S., and Salter, R. D. (2010). Identification and characterization of a novel variant of the human $\mathrm{P} 2 \mathrm{X} 7$ receptor resulting in gain of function. Purinergic Signal. 6, 31-45. doi: 10.1007/s11302-0099168-9

Sun, C., Heid, M. E., Keyel, P. A., and Salter, R. D. (2013). The second transmembrane domain of $\mathrm{P} 2 \mathrm{X} 7$ contributes to dilated pore formation. PLoS One 8:e61886. doi: 10.1371/journal.pone.0061886

Surprenant, A., Rassendren, F., Kawashima, E., North, R. A., and Buell, G. (1996). The cytolytic P2Z receptor for extracellular ATP identified as a P2X receptor (P2X7). Science 272, 735-738. doi: 10.1126/science.272.5262. 735

Tatham, P. E., and Lindau, M. (1990). ATP-induced pore formation in the plasma membrane of rat peritoneal mast cells. J. Gen. Physiol. 95, 459-476. doi: 10. 1085/jgp.95.3.459

Toulme, E., Soto, F., Garret, M., and Boue-Grabot, E. (2006). Functional properties of internalization-deficient $\mathrm{P} 2 \mathrm{X} 4$ receptors reveal a novel mechanism of ligandgated channel facilitation by ivermectin. Mol. Pharmacol. 69, 576-587. doi: 10. 1124/mol.105.018812

Tran, J. N., Pupovac, A., Taylor, R. M., Wiley, J. S., Byrne, S. N., and Sluyter, R. (2010). Murine epidermal langerhans cells and keratinocytes express functional P2X7 receptors. Exp. Dermatol. 19, e151-e157. doi: 10.1111/j.1600-0625.2009. 01029.x

Vassort, G. (2001). Adenosine 5'-triphosphate: a P2-purinergic agonist in the myocardium. Physiol. Rev. 81, 767-806.

Virginio, C., Mackenzie, A., North, R. A., and Surprenant, A. (1999a). Kinetics of cell lysis, dye uptake and permeability changes in cells expressing the rat P2X7 receptor. J. Physiol. 519(Pt 2), 335-346. doi: 10.1111/j.1469-7793.1999. $0335 \mathrm{~m} . \mathrm{x}$
Virginio, C., Mackenzie, A., Rassendren, F. A., North, R. A., and Surprenant, A. (1999b). Pore dilation of neuronal P2X receptor channels. Nat. Neurosci. 2, 315321. doi: $10.1038 / 7225$

Virginio, C., North, R. A., and Surprenant, A. (1998). Calcium permeability and block at homomeric and heteromeric P2X2 and P2X3 receptors, and P2X receptors in rat nodose neurones. J. Physiol. 510(Pt 1), 27-35. doi: 10.1111/j. 1469-7793.1998.027bz.x

Wesselius, A., Bours, M. J., Agrawal, A., Gartland, A., Dagnelie, P. C., Schwarz, P., et al. (2011). Role of purinergic receptor polymorphisms in human bone. Front. Biosci. (Landmark Ed.) 16, 2572-2585. doi: 10.2741/3873

Yan, Z., Khadra, A., Li, S., Tomic, M., Sherman, A., and Stojilkovic, S. S. (2010). Experimental characterization and mathematical modeling of P2X7 receptor channel gating. J. Neurosci. 30, 14213-14224. doi: 10.1523/jneurosci.239010.2010

Yan, Z., Khadra, A., Sherman, A., and Stojilkovic, S. S. (2011). Calcium-dependent block of P2X7 receptor channel function is allosteric. J. Gen. Physiol. 138, 437452. doi: 10.1085/jgp.201110647

Yan, Z., Li, S., Liang, Z., Tomic, M., and Stojilkovic, S. S. (2008). The P2X7 receptor channel pore dilates under physiological ion conditions. J. Gen. Physiol. 132, 563-573. doi: 10.1085/jgp.200810059

Yan, Z., Liang, Z., Obsil, T., and Stojilkovic, S. S. (2006). Participation of the Lys313-Ile333 sequence of the purinergic P2X4 receptor in agonist binding and transduction of signals to the channel gate. J. Biol. Chem. 281, 32649-32659. doi: 10.1074/jbc.m512791200

Zemkova, H., Yan, Z., Liang, Z., Jelinkova, I., Tomic, M., and Stojilkovic, S. S. (2007). Role of aromatic and charged ectodomain residues in the P2X4 receptor functions. J. Neurochem. 102, 1139-1150. doi: 10.1111/j.1471-4159. 2007.04616.x

Conflict of Interest Statement: The authors declare that the research was conducted in the absence of any commercial or financial relationships that could be construed as a potential conflict of interest.

Received: 13 September 2013; accepted: 29 October 2013; published online: 14 November 2013.

Citation: Rokic MB and Stojilkovic SS (2013) Two open states of P2X receptor channels. Front. Cell. Neurosci. 7:215. doi: 10.3389/fncel.2013.00215

This article was submitted to the journal Frontiers in Cellular Neuroscience.

Copyright ( 2013 Rokic and Stojilkovic. This is an open-access article distributed under the terms of the Creative Commons Attribution License (CC BY). The use, distribution or reproduction in other forums is permitted, provided the original author (s) or licensor are credited and that the original publication in this journal is cited, in accordance with accepted academic practice. No use, distribution or reproduction is permitted which does not comply with these terms. 